\title{
Quality teaching through openness and collaboration - an alternative to the TEF?
}

\author{
Chrissi Nerantzi
}

\begin{abstract}
In this opinion piece, I offer an alternative vision to the TEF that positions universities at the heart of communities and society through greater collaboration among higher education institutions and involving the wider public. I argue that this approach is a rewarding way for academic staff to innovate and develop their teaching capabilities, so as to improve the student experience and outcomes at universities. This contrasts with a TEF model of measurement of indicators as proxies for teaching quality.
\end{abstract}

\section{Boundary-crossing professional development}

Learning and development should be lifelong, lifewide and lifedeep (Bell, 2012) and universities and their people play a key role in modelling such ways of being and becoming (Barnett, 2007). We academic staff have a passion for experimenting, creating, debating and sharing ideas and knowledge that helps others, the community, and society more widely. It's vital that, now and in the future, we find imaginative ways to inspire staff and students to teach and learn within and across subject boundaries; perhaps only this inter-disciplinary collaboration will lead to those novel connections of ideas and people that generate discovery and drive innovation.

The UK HE system is already ahead of many other countries in recognising the importance of quality teaching: we have dedicated in-house teaching qualifications, nationally-recognised professional standards and institutional provision for initial and continuous professional development. To support these activities, most UK universities have an academic development unit. Even so, academic developers are often criticised for being slow both to embrace new pedagogies and technologies and to encourage in staff a willingness to share ideas, reflect, act upon insights and innovate (Education Technology Action Group, 2015). In this context, there is now greater pressure to raise the quality of teaching and achieve excellence, in the shape of formulae linked to financial incentives - something guaranteed to increase competition among HEIs (BIS, 2016a; 2016b). The TEF is a UK Government initiative that aims to achieve teaching excellence through published benchmarking of $\mathrm{HEI}$ with the added incentive of linking results to the opportunity to increase student fees. This has the potential for yet greater competition between universities. Just what will be the impact of such pressures upon students and staff in 


\section{TEF Special Edition}

these institutions? And upon the HE sector as a whole? Other voices need to be heard and alternative practices need to be considered.

My research is in the area of academic development through open, cross-institutional collaboration; as such, it constitutes an alternative voice. In a recent phenomenographic study, I explored the lived collaborative open-learner experience in openly-licensed cross-institutional and practitioner-driven academic development courses (Nerantzi, work-in-progress). These were the Flexible, Distance and Online Learning (FDOL132) and Creativity for Learning in HE (\#creativeHE) courses; teachers in HE, students and members of the public from a range of backgrounds and cultures came together to discuss, debate and develop, both formally and informally within such cross-boundary communities, and both online and offline. These open courses have the characteristics of what Weller (2011) calls 'little' Open Educational Resources and utilise freely-available social media. Whilst the study had a focus on the UK, its open and collaborative nature meant that it extended beyond geographical, cultural and political borders. Collaboration and openness were explored as a means of breaking free from institutional walls and silos and of bringing individuals from different backgrounds and cultures together to develop HE teaching within diverse cross-boundary communities.

This developmental vehicle provided clear evidence of individual and collective growth; it strengthened relationships, brought together fresh ideas and perspectives that were valued by participants, kept them engaged and created a sense of belonging to a diverse learning community. This mixing of individuals makes a real difference to engagement in this type of academic professional development, as it is proactive and interest-driven; it brings together diverse perspectives, ideas and people who feel empowered to take risks and make innovative changes to their teaching practice. For example, academic staff found it particularly valuable to learn with individuals from outside $\mathrm{HE}$, as they brought new perspectives and ideas; students developed confidence while working with academic staff and felt that they had contributed to coshaping university teaching.

At the same time as the UK Government is rolling out the TEF, which seeks to categorise, rank and compare universities (with, inevitably, increased competition), there is a call for more openness and collaboration among HEls, as it is recognised that such approaches enrich the student and staff experience (European Commission, 2013; European Commission, 2015; HEFCE, 2011); my own study also confirms this. 


\section{TEF Special Edition}

\section{Food for thought}

I am unconvinced that competitiveness is the way to achieve sector-wide teaching excellence or even that teaching excellence is the dream we should chase. My study shows that open, collaborative and cross-boundary approaches bring staff, students and the public together. Through these, we grow and spread innovative teaching practices underpinned by continuous professional development; we inspire staff and students as well as position universities at the heart of local and distributed communities and society. How, without further competitiveness, could we remodel the TEF to measure the quality of teaching and incorporate openness, crossinstitutional collaboration, teacher development and innovation?

\section{Acknowledgements}

I would like to thank Simon Walker, Viv Vladimirschi and Dr Stephen Powell for reading the first drafts of this article as well as the reviewers for their valuable suggestions.

\section{Reference list}

Barnett, R. (2007) A will to learn. Being a student in an age of uncertainty, Maidenhead: Open University Press.

Bell, P. (2012) 'Life-long, life-wide, and life-deep learning.' In: J. A. Banks (ed.), Encyclopedia of diversity in education, 4, 1395-1396. Thousand Oaks, CA: SAGE Publications Ltd.

BIS (2013b) 'Participation rates in higher education: Academic years 2006/2007 - 2011/2012.' (provisional) Department for business, innovation \& skills. London: BIS. Available at: https://www.gov.uk/government/uploads/system/uploads/attachment_data/file/306138/13-p140HEIPR_PUBLICATION_2011-12_2_.pdf (Accessed: 6 January 2017).

BIS (2016a) 'Success as a knowledge economy: Teaching excellence, social mobility \& student choice.' Department for business, innovation \& skills. London: BIS. Available at: https://www.gov.uk/government/uploads/system/uploads/attachment_data/file/523396/bis-16265-success-as-a-knowledge-economy.pdf (Accessed: 6 January 2017). 


\section{TEF Special Edition}

Education Technology Action Group. (2015) Our reflections, ALT. Available at: https://drive.google.com/file/d/0B_4FnLyL2BFvMjBOVFY4ZnhRVTA/view (Accessed: 6 January 2017).

European Commission (2013) High level group on the modernisation of higher education. Report to the European commission on improving the quality of teaching and learning in Europe's higher education institutions. European Union. Available at:

http://ec.europa.eu/education/higher-education/doc/modernisation_en.pdf (Accessed: 6 January 2017).

European Commission (2015) Draft 2015 joint report of the council and the commission on the implementation of the strategic framework for European cooperation in education and training (ET2020). New priorities for European cooperation in education and training, Brussels:

European Commission. Available at: http://ec.europa.eu/education/documents/et-2020-draftjoint-report-408-2015_en.pdf (Accessed: 6 January 2017).

HEFCE (2011) Collaborate to compete - Seizing the opportunity of online learning for UK higher education. Available at: http://bit.ly/gZloBB (Accessed: 6 January 2017).

Nerantzi, C. (work in progress) Towards establishing a cross-boundary collaborative open learning framework for cross-institutional academic development. (PhD thesis), Edinburgh: Edinburgh Napier University.

Weller, M. (2011) The digital scholar. How technology is transforming scholarly practice. London: Bloomsbury Academic. 